\title{
Topological Optimization for Pick Cutter of Roadheader Based on Hypermesh
}

\author{
Qingliang Zeng ${ }^{1, ~ a, ~ X i n c h a o ~ W a n g ~}{ }^{1, b^{*}}$, Qiang $\mathrm{Gu}^{2, \mathrm{c}}$, Zhongyan Gao ${ }^{1, \mathrm{~d}}$ \\ ${ }^{1}$ College of Mechanical and Electronic Engineering, Shandong University of Science and \\ Technology, Qingdao, China \\ ${ }^{2}$ College of Electrical Engineering and Automation, Shandong University of Science and \\ Technology, Qingdao, China \\ aqlzeng@163.com, b18754277910@163.com, ${ }^{c}$ guqiang0537@163.com, \\ dgaozhongyan26@163.com
}

Keywords: pick cutter, lightweight, topological optimization, fatigue life

Abstract. In order to optimize the structure of the pick cutter under the premise to meet its performance, and to achieve their own weight, the pick cutter of the longitudinal axis roadheader, which works under complicated seam conditions, is regarded as the research object. Based on the finite element method, statics strength analysis and fatigue life analysis of pick cutter are finished. According to the analysis results, the arbor of pick cutter is regarded as the object for topological optimization based on the variable density method. For the optimized structure, the necessary analysis is finished to verify its strength and fatigue life. The result shows that the optimized pick cutter satisfies the requirements with $24 \%$ weight reduction. It provides some reference for structure design, improvement and further research of pick cutter, and has a high guidance and practical value.

\section{Introduction}

Due to withstand impact loads, the pick cutter would be worn, chipping, lost teeth and fracture phenomena, and it will reduce the production efficiency of the roadheader and extend its downtime[1]. Currently, the design and manufacture of the pick cutter is mostly based on traditional experience[2], and their basic structure has not changed. It will lead to the problem of properties surplus under different conditions.

Therefore, in the actual operating conditions, the structural optimization of pick cutters based on traditional experience design is its guarantee for optimal performance and lightweight. In this paper, the pick cutter of a domestic-type longitudinal axis roadheader is regarded as the study and analysis object for static strength and fatigue life based on the finite element analysis software Hypermesh. According to the analysis results and the actual production needs, the pick cutter carries on topology optimization and structural improvements, and the strength and fatigue life of the optimized pick cutter will be verified.

\section{Finite Element Analysis of the pick cutters}

The finite element model for the pick cutter is established, and the load spectra is simulated by Matlab. According to the relevant research, the position of force and constraints are applied[3 6].

\section{Analysis of Static Strength}

According to the finite element model and obtained load spectra of the pick cutter, the maximum of suffered three forces is determined, namely the cutting resistance $45.280 \mathrm{KN}$, feeding 
resistance $24.181 \mathrm{KN}$, lateral force $10.839 \mathrm{KN}$. This is the most dangerous working condition. Based on the finite element method, the RADIOSS solver of Hypermesh software is used for the statics strength analysis of pick cutter and getting the displacement and stress contour, as shown in Figure 1.

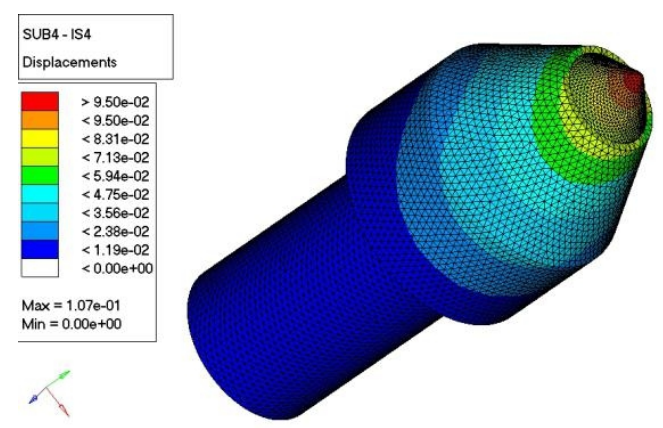

( a ) Displacement contour

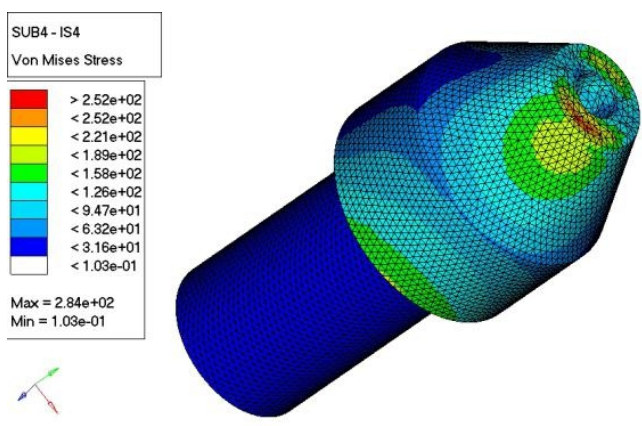

( b ) Stress contour

Fig.1 Analysis of results

As shown in figure 1, the maximum displacement of the pick cutter under the most dangerous conditions appears in the cutter head. It is $0.107 \mathrm{~mm}$. This displacement amount is so small that it has little effect on the properties of pick cutters. It meets the stiffness requirements of pick cutter. Since the maximum stress of the arbor appears at the convergence between the arbor and the tip in actual use, as $284 \mathrm{MPa}$, which is less than the arbor material $42 \mathrm{CrMo}$ allowable stress $[\sigma]=$ $310 \mathrm{MPa}$, it meets the strength requirements of pick cutter.

\section{Analysis of Fatigue Life}

Using the nominal stress method, based on the theory of linear fatigue damage accumulation, through rain flow counting method to deal with the simulated load spectrum and according to the material and survival of the arbor, the S-N curve of the material is obtained. Considering the average stress method, fatigue strength coefficient and stress combined method and other factors, the fatigue life cloud of the arbor of the pick cutter is obtained by the Fatigue Progress Manager module in Hypermesh software, the results shown in Figure 2.

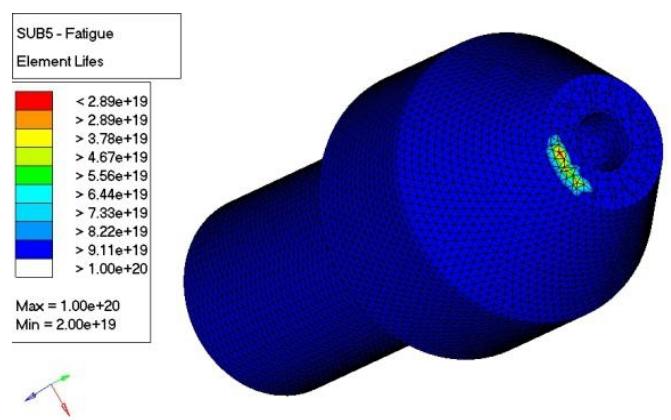

Fig.2 Analysis of results

As shown in figure 2, the most prone to fatigue failure part of the cutter arbor is located at the junction between the arbor and the head. The minimum fatigue life is $2.89 \mathrm{e} 19$ loading cycles.It can be considered that cutters fatigue damage will not occur. It meets the fatigue life requirements.

\section{Topology optimization analysis and result verification}

\section{Topology Optimization Analysis and Structure Improvement}

According to the statics strength and fatigue life analysis of pick cutter, the damage doesn't occur in theory condition. Because of the complicated working condition, the pick cutter has the 
problem of excess performance. According to the relevant study, it shows that the life of new pick cutter is generally 8 hours to 35 hours[7,8]. Therefore, the structure optimization of pick cutter is needed to get its optimal performance.

The working conditions of domestic certain longitudinal axis roadheader is set, 24-hour working system, cutting head speed of 50r / min, the design fatigue life of 30 days, the arbor's allowable stress of $310 \mathrm{MPa}$. Based on the variable density method, topological optimization of arbor runs by Optistruct model in Hypermesh. In this optimization, the aim is to realize the minimum volume with the constraints of material allowable stress and given fatigue life. The results shows in Figure 3.
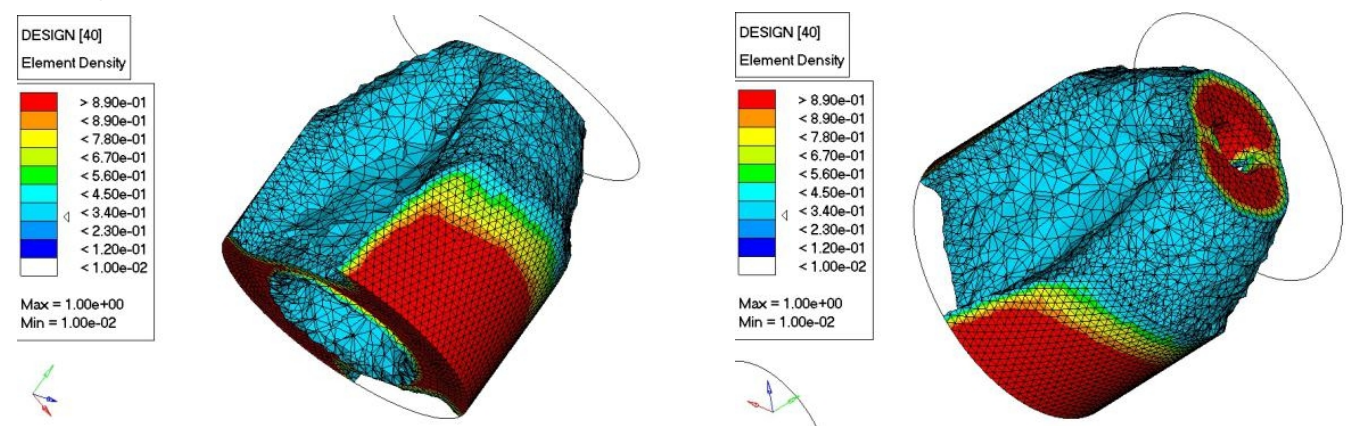

Fig.3 Optimization results

Considering that the pick cutter has a rotation feature in the actual work process, so it needs to do some structural redesign after exporting the topology optimization result in order to realize the rotation characteristics and symmetrical structure. Using the OSSmooth model in Hypermesh to export the topology optimization result, improve and redesign the structure of pick cutter by Solidworks. The structure after improvement and redesign shows in Figure 4.

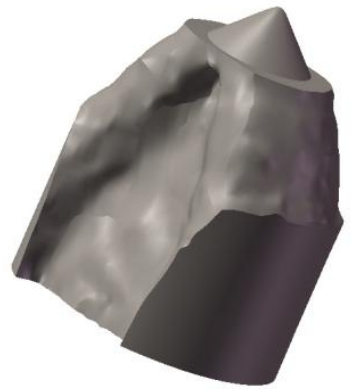

(a) The optimized model after exporting

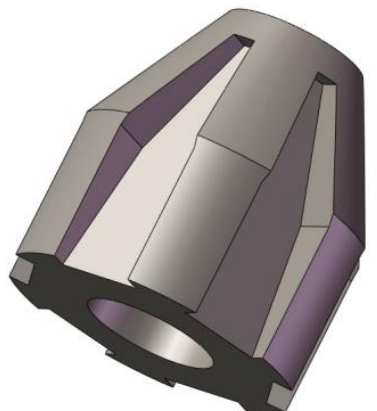

(b) Optimized model after improving

Fig.4 Structurcal improvement

As shown in figure 4, the optimized pick cutter has three parts, including cutter head, cutter head seat and cutter handle. The cutter head is installed on the cutter head seat by welding, and the seat couples with the cutter handle by bolt. The installation way realizes faster replacement, so that the parts of pick cutter which still work can use a longer time. In terms of mass, compared with the pick cutter before optimization, the optimized alleviates $0.432 \mathrm{~kg}$, namely reduced by $24 \%$, so that it can realize the lightweight.

\section{Optimization results verification}

Through the establishment of three-dimensional model of the optimized pick cutter, import the model into Hypermesh to build its finite element model. Based on the FEA methods and parameters which are set before, the strength analysis and fatigue life analysis are run by Hypermesh. The results shows in figure 5 . 


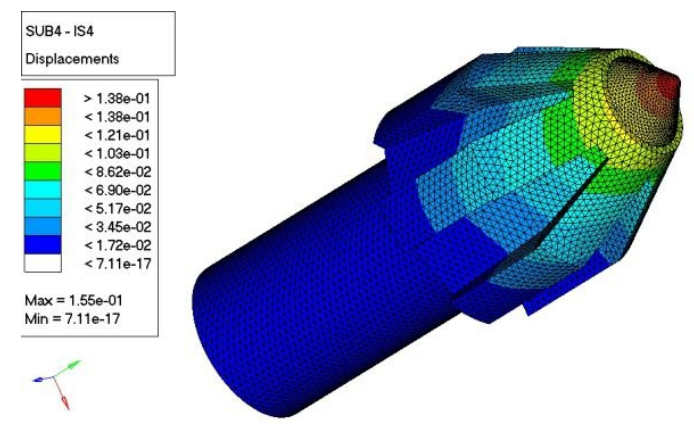

(a) The displacement contour

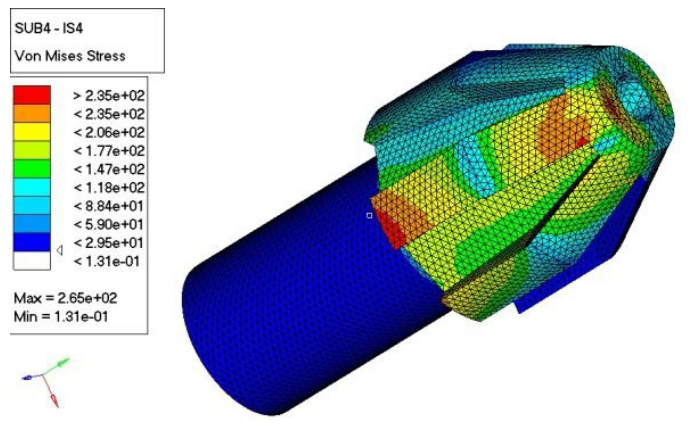

(b) The stress contour

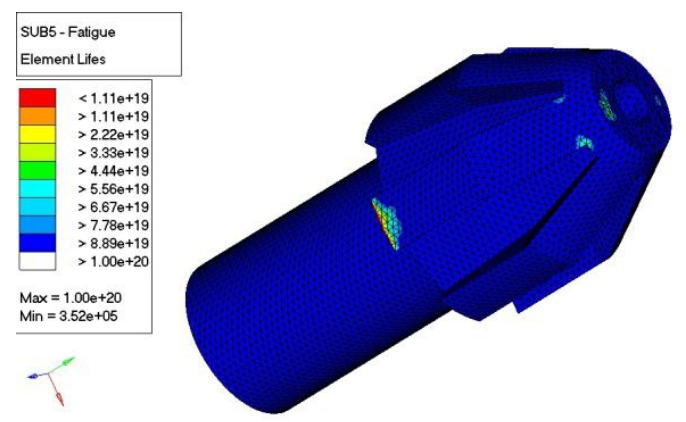

(c) The life contour

Fig.5 The analysis result

As shown in figure 5, the maximum displacement of the optimized pick cutter reaches $0.155 \mathrm{~mm}$, under the most dangerous condition. It occurs in the blade portion of pick cutter. Compared with the structure size, the displacement is too small to influence its performance, so it meets the stiffness requirements of pick cutter. The maximum stress occurs in the contact area between the cutter head seat and pick cutter block. It is $265 \mathrm{MPa}$, less than $310 \mathrm{MPa}$, which is the material allowable stress of $42 \mathrm{CrMo}$, so it meets the strength requirements of pick cutter. The lowest fatigue life is $3.52 \mathrm{e} 5$ times loading cycles, which occurs in the contact area between the cutter head seat and pick cutter block.

$$
N=\frac{3.52 e 5 \times 10}{24 \times 50 \times 60}=48.88
$$

Namely, according to the calculation, the maximum life of the optimized pick cutter can reach 48.88 days, and it meets the given life 30 days, so it satisfies the fatigue requirements. In addition, if the pick cutter occurs fatigue damage, it can be used again after restoration to extend its life.

\section{Summary}

Based on Hypermesh, the static strength analysis and fatigue life analysis of pick cutter are finished. According to the analysis results and the actual working condition, the structure of pick cutter carries on topological optimization, and structural improvement. Then the static strength and fatigue life are verified for the optimized structure.

The conclusions are as follows.

(1) The mass of the optimized pick cutter has reduced $0.432 \mathrm{~kg}$, and it realizes the less material and lightweight of pick cutter.

(2) The results of static analysis shows that the maximum stress of the optimized pick cutter is less than the previous one, and the maximum stress occurs in different part. But, the optimized pick cutter meets the strength requirements.

(3) Compared with the displacement contour of the previous pick cutter, it is the same place where the maximum displacement occurs in the optimized one, but it is larger than the previous. 
The optimized pick cutter meets the stiffness requirements.

(4) The results of fatigue life analysis shows that the place where the maximum fatigue life occurs is different between the previous pick cutter and the optimized one. It meets the fatigue life requirements for the optimized.

\section{Acknowledgements}

This paper is supported by Science and Technology Innovation Foundation for Graduate Students of Shandong University of Science and Technology (Grant No.YC150326), National Natural Science Foundation of China (Grant No.51375282), and Program for Changjiang Scholars and Innovative Research Team in University (Grant No.IRT1266). The authors have declared that no conflict of interest exists.

\section{Reference:}

[1] Li Xiaohuo. Failure Analysis of Pick for Roadheader and Boring Machine, J. Mining \& Processing Equipment. 8 (1999) 20-21.

[2] Yin Huanxing. Design and Research for Self-sharpening Pick of Loadheader, D. Shenyang Ligong University. (2012).

[3] Bie Long, etc. Cutting Principle of Coal and Rock. China Industry Press, Beijing, 1965.

[4] Li Xiaohuo. Design and Research of Roadheader's Cutting Head. China's overseas Chinese press, Beijing, 1997.

[5] Yu Kaiping, Zhou Chuanyue, Tan Huifeng, etc. HyperMesh From Entry to the Master. Science Press, Beijing, 2005.

[6] Wang Dan. The Mechanical Property and Parameter Optimization for Cutting Mechanism of Vertical Axis Hard Rock Roadheader . D. Liaoning Technical University. (2009).

[7] A.W. Kyle, etc. Periodic replacement cutter reduce the amount of dust generated. J. The world coal technology. 2 (1994) 34-35.

[8] Cai Heping, Zhu Weidou, etc. Thermal Fatigue Failure Analysis of Cemented Carbide on Hard Coal Cutter Blade. J. Journal of Xi’An Jiaotong University, 3 (1997) 12-17. 